\title{
Antiepileptic drugs: coprescription of proconvulsant drugs and oral contraceptives: a national study of antiepileptic drug prescribing practice
}

\author{
S D Shorvon, R C Tallis, H K Wallace
}

J Neurol Neurosurg Psychiatry 2002;72:114-115

Objectives: To determine the frequency of coprescription of antiepileptic drugs (AEDs) and drugs with proconvulsant potential and of coprescription of AEDs and low dose oral contraceptives.

Methods: Using information from all 294 fully computerised general practices participating in the General Practice Research Database who entered complete data in 1995, persons were identified who had a prescription for an antiepileptic drug and who had a diagnosis of epilepsy or epileptic seizures in their medical records. Other medication was also recorded.

Results: Of women with epilepsy aged 15-45, 16.7\% were on the oral contraceptive pill and of 200 on both an enzyme inducing AED and an oral contraceptive, 56\% were on formulations with an estrogen content less than 50 $\mu \mathrm{g}$. This will be associated with increased risk of contraceptive failure and unwanted pregnancy. Over 10\% of all AED prescriptions in adults were associated with simultaneous prescription of at least one drug with a potential proconvulsant effect.

Conclusions: Prescribers should be alert to the possibility of pharmacodynamic and pharmacokinetic interactions between AEDs and other medication. With the aging of the population of people with seizures, and the polypharmacy often associated with old age, the likelihood of adversely interacting drug combinations will increase.

O ver $99 \%$ of people in the United Kingdom are registered with a general practitioner, providing a unique source of epidemiological data for studying the health and morbidity of unselected population based groups of patients. The United Kingdom Office for National Statistics General Practice Research Database (GPRD) holds anonymised records of 3.6 million patients in over 500 general practices in England and Wales, representing over 6\% of the total population of England and Wales. This source of continuous data on the diagnosis and treatment of illness in general practice has been extensively validated. ${ }^{1}$

The population of people with seizures is aging ${ }^{23}$ and multiple pathology and polypharmacy are very common in older people. ${ }^{4}$ A possible cause of poor control of seizures by antiepileptic drugs (AEDs) is the coprescription of drugs which may lower the seizure threshold. The present study uses the GPRD to explore the hypothesis that concurrent prescription of proconvulsant drugs may occur in a significant proportion of patients with epilepsy.

Another important interaction of AEDs is with oral contraceptives as the efficacy of low dose estrogen preparations may be impaired by enzyme inducing AEDs. The present study also examines the extent to which AEDs were coprescribed with oral contraceptives.

\section{METHODS \\ Population and case ascertainment}

We used information from all 294 fully computerised general practices participating in the GPRD who entered complete data in 1995. Patients were included who had received a prescription for an antiepileptic drug during the study year and who had a diagnosis of epilepsy or epileptic seizures in their medical record. No attempt was made to separate incident from prevalent cases.

To identify the cases, the database was searched for:

(1) All diagnostic codes which denote the various epilepsy syndromes and seizure types (and using various synonyms for epilepsy such as "seizure" etc).

(2) Codes for all the different formulations of 11 AEDs: carbamazepine, clobazam; clonazepam, ethosuximide, gabapentin, lamotragine, phenobarbital, phenytoin, sodium valproate, topiramate, and vigabatrin.

The age and sex distributions of the base populations were determined for the practices.

\section{Diagnostic validity and reliability}

The GPRD is a complex computerised system, set up primarily prospectively to track prescribing data. The participating general practices enter all drugs prescribed, a diagnosis/indication for each new prescription, the initial indication for any repeat prescriptions, and all instances of significant morbidity. The entries are recorded directly onto the computer system by the general practitioner in the surgery each time a patient is seen. The representativeness of the database is demonstrated by the almost identical age and sex distribution of the database population with that of the general population.

There have been extensive studies of the validity of the prescribing data, with good agreement between the GPRD and the Prescription Pricing Agency (PPA) prescribing data for CNS (and other) drugs, although AEDs have not been studied separately. The validity of the diagnostic data has also been studied in diabetes, asthma, and schizophrenia, and all have shown over $90 \%$ diagnostic completeness. ${ }^{1}$ The aspects of care most reliably addressed by the GPRD are those related to medication, as the database was originally set up by the VAMP software company to record drug prescribing practice in adverse events. As drugs are a component of treatment for the vast majority of patients, epilepsy is a particularly suitable condition to investigate using the database.

\section{Questions under investigation}

Using the complete data set of 294 practices, we investigated for the year 1995:

Abbreviations: AEDs, antiepileptic drugs; GPRD, general practice research database; PPA, Prescription Pricing Agency 


\begin{tabular}{|c|c|c|}
\hline \multicolumn{3}{|c|}{$\begin{array}{l}\text { Table } 1 \text { Numbers of adults and } \\
\text { children in the epilepsy and total } \\
\text { patient populations in each dataset }\end{array}$} \\
\hline & $\begin{array}{l}\text { All epilepsy } \\
\text { cases }\end{array}$ & $\begin{array}{l}\text { Total patient } \\
\text { population }\end{array}$ \\
\hline $\begin{array}{l}\text { Adults } \\
\text { Children }\end{array}$ & $\begin{array}{l}9267 \\
1297\end{array}$ & $\begin{array}{l}1637831 \\
415091\end{array}$ \\
\hline
\end{tabular}

Table 2 Number of prescriptions for proconvulsant medication in the population of adults with epilepsy

\begin{tabular}{ll}
\hline Proconvulsant & Number \\
\hline Tricyclic antidepressants & 735 \\
Phenothiazines & 734 \\
Aminophylline & 27 \\
Antimalarials & 15 \\
Lithium & 14 \\
Theophylline & 11 \\
Amphetamine & 1 \\
Disopyramide & 1 \\
Total & 1538 \\
\hline
\end{tabular}

(1) The use of the oral contraceptive pill with AEDs.

(2) The use of proconvulsant drugs with AEDs. (Only those cases where the AED prescription precedes the prescription for the proconvulsant were considered.)

\section{RESULTS}

Table 1 gives a breakdown of the numbers of adults and children in the epilepsy and total patient populations in each data set.

\section{The use of oral contraception}

In 1995, 16.7\% (390/2341) of women with epilepsy aged 15-45 were taking the oral contraceptive pill, compared with a proportion of about $25 \%$ for the general population of women between these ages. Of 200 women taking both an enzyme inducing AED (carbamazepine, phenytoin, or phenobarbital) and an oral contraceptive, $56.5 \%$ were taking formulations with an estrogen content less than $50 \mu \mathrm{g}$ and $43.5 \%$ were on a compound of $50 \mu \mathrm{g}$ or more.

\section{The use of proconvulsant drugs}

In 1995, in 10.9\% (1404/12909) of all AED prescriptions in adults there was a simultaneous prescription for at least one proconvulsant drug. A total of 1270 AED prescriptions were associated with a prescription for one proconvulsant drug, 132 for two, and one for three, representing a total of 1538 proconvulsant prescriptions in all (table 2).

\section{DISCUSSION}

The concern prompting this study that patients on AEDs might be on coprescribed medication which could have adverse interactions has proved to be justified. Over $10 \%$ of all
AED prescriptions in adults were associated with a simultaneous prescription of at least one proconvulsant drug. It is difficult to judge the appropriateness of the coprescription of proconvulsant drugs but the high prevalence is worrying. Not surprisingly, tricyclic antidepressant drugs and phenothiazines between them account for the vast majority of coprescribed proconvulsant drugs. The frequent coprescription of phenothiazines in patients with epilepsy presumably reflects the fact that seizures may be associated with learning difficulties, psychosis, or behavioural disturbances or, in later life, dementing illness such as multi-infarct dementia. The coprescription, in almost $5 \%$ of cases, of tricyclic antidepressants is worrying as these are increasingly recognised as a cause of minor status in older people. ${ }^{5}$ Over 40 coprescriptions were due to theophyllines or aminophyllines, which have very unpredictable toxic responses in older people ${ }^{67}$ and are not infrequently seen in toxic levels.

Less than half of the women on enzyme inducing AEDs are on a high estrogen content contraceptive pill. The efficacy of the pill is reduced by enzyme inducing AEDs and women who are on such AEDs should not be prescribed low dose estrogen preparations. This hazard of contraceptive failure and an unwanted pregnancy is entirely avoidable.

Prescribers should be alert for the possibility of pharmacodynamic and pharmacokinetic interaction between AEDs and other medication. In cases where patients' seizures seem difficult to control, the possibility of coprescription of a proconvulsant drug should be entertained.

\section{ACKNOWLEDGEMENTS}

We thank the ONS for their help in providing data for this paper.

\section{Authors' affiliations}

S D Shorvon, H K Wallace, Epilepsy Research Group, Institute of Neurology, Queen Square, London WCIN 3BG, UK

R C Tallis, Division of Geriatric Medicine, Clinical Division 1, University of Manchester, Clinical Sciences Building, Hope Hospital, Eccles Old Road, Manchester M6 8HD, UK

Correspondence to: Professor R C Tallis, Division of Geriatric Medicine, Clinical Division 1, University of Manchester, Clinical Sciences Building, Hope Hospital, Eccles Old Road, Manchester M6 8HD, UK;

Received 1 March 2001

In revised form 20 July 2001

Accepted 6 August 2001

\section{REFERENCES}

1 Jick $\mathbf{H}$, Jick SS, Derby LE. Validation of Information recorded on a general practitioner based computerised data resource in the UK. BM $1991 ; 302: 766-8$

2 Wallace $\mathbf{H}$, Shorvon S, Tallis R. Age-specific incidence and prevalence rates of treated epilepsy in an unselected population of 2,520,922 and age-specific fertility rates for women with epilepsy. Lancet 1998;352:1970-3.

3 Hauser WA, Annegers JF, Kurland LT. Prevalence of epilepsy in Rochester, Minnesota: 1940-1980. Epilepsia 1991;32:429-45.

4 Crome P. Adverse drug reactions in: Crome P, Ford G, eds. Drugs and the older population. London: Imperial College Press, 2000.

5 Thomas P, Beaumanoir A, Genton P, et al. De novo absence status of late onset: Report of 11 cases. Neurology 1992;42:104-10.

6 Sessler CN. Theophylline toxicity; clinical features in 116 consecutive cases. Am J Med 1990;88:567-76.

7 Shannon M, Lovejoy FH. The influence of age $-v-$ peak serum concentration on life-threatening events after chronic theophylline intoxication. Arch Intern Med 1990;150:2045-8. 